\title{
International Legislation in the Field of Astronomical Nomenclature
}

\author{
Liliya Kazantseva
}

Candidate of physical and mathematical sciences, the Head of the Astronomical Museum, Taras Shevchenko National University of Kyiv

(Kyiv, Ukraine)

E-mail: Kazantsevaliliya1@gmail.com

https://orcid.org/0000-0001-8289-3954

The names of celestial objects and natural formations on the Earth's surface take into account historical trends and certain generalized systematics. National and regional names are more used in relation to anthropogenic objects. The decision to assign a name to a celestial body is made by the relevant international structures through a preliminary long-term study. International and national legal acts, regulating the sphere of astronomical nomenclature, are analyzed.

Keywords: astronomical nomenclature, space law, astronomical names

Received: September 27, 2019; accepted: November 01, 2019

Advanced Space Law, Volume 4, 2019: 19-25.

https://doi.org/10.29202/asl/2019/4/2

\section{Introduction}

There are times when, as a sign of sincere gratitude, admiration "in memory of" or from a distant calculation, one person or persons want to give another one something unusual and unique, in addition naming in honour of the lucky one. It is good if the donators have such a thing or object, otherwise, in case of a car, TV, perfume or any material thing made or designed not by you, it is difficult to rename, it is already clear to everyone. You can give a named villa, yacht, hotel, company or firm, fund. And if you want something bigger or large-scale? Village, river, maybe sea or ocean, island, continent? Here everyone understands that it will not be possible. But the star to give, call it whatever you want, paying a lot of money and getting a beautiful multi-colored certificate, someone considers it as a good gift option to another person or even oneself. And is it really so? In practice, as a result of unclear provisions of international law and existing legal gaps in the "Outer Space Treaty", certain individuals, in fact, appropriate space objects that are the property of the whole community [Svitlychnyy, 2019].

(C) Kazantseva, Liliya, 2019 


\section{Legal basis for naming objects on Earth's surface and assigning them the names of real persons}

Regulation of relations and activities concerning the establishment of names of geographical objects in the country, their regulation, registration and accounting, use and storage are prescribed in the Constitution of Ukraine [Konstytutsiia, 1996], the law on geographical names [Pro heohrafichni nazvy, 2005], and the Code of established practice "Structure and content of the State register of geographical names" [Kodeks, 2009]

According to the Ukrainian legislation, each integral and relatively stable formation on the Earth of natural or anthropogenic origin, which exists or existed in the past and is characterized by a certain location, acts as a geographical object. This applies to both large creators of the landscape (continents, seas and oceans) and continental components (ice sheets, steppes, plains), and smaller formations: fluval, that is, created as a result of the geological action of temporary or permanent watercourses (rivers and streams, swamps and waterfalls, estuaries and their deltas and valleys, dams, floodplains, canyons and caves, ponds and lakes, rapids and beaches, meanders and oases); mountain (mountains and ranges, hills and plateaus, ridges and outcrops); coastal (atolls and shelves, bays and isthmuses, islands, peninsulas, capes and lagoons, coasts); volcanic (volcanoes themselves and their craters, lava plateaus and domes, geysers and caldera); aeolian, or sediments formed by wind (dunes and deserts).

The law also covers geographical objects created by people: reservoirs, dams, quarries, tunnels, roads and bridges, settlements and streets, railway stations, airports, marinas.

None of these objects can be renamed by paying money. There is a clear and understandable procedure for giving them their own names in honor of famous personalities by local or central authorities.

As the Law specifies, for recognition and establishment of distinction of a certain geographical object from others, it is given the name which is established by research of existing or known in the past historical names, names and renames. Further there is a discussion of names and the most used and acceptable of them is chosen. At the same time, its writing in the state language is carried out according to certain rules. In the next stage, the name is approved by the relevant geographical names authorities and noted in state registers and placed on official maps.

The use of surnames that occur in geographical names show a person's direct relation to this object (participation in the discovery, research, creation or foundation), or great respect for this person, for his feat, biography or a certain action (posthumously and in exceptional cases, taking into account the opinion of the local population).

When naming objects or assigning them names (pseudonyms) of individuals, anniversary and holiday dates, names and dates of historical events, their location, purpose, geographical, historical, toponymic, cultural, architectural and other features, local traditions of the name should be taken into account.

A number of geographical objects have long been named after well-known travelers and researchers. This, for example, is a river in New York state, USA and a strait in the Arctic ocean that washes the shores of Canada, which are named after the Navigator Henry Hudson, who in 1607 made a journey to reach India and China through the North pole. Livingstone falls on the Congo river in Central-West Africa were named in 1877 after the Scottish Explorer of Africa missionary David Livingstone. Mount Fitz-Roy, which is located on the border between Argentina and Chile and one of the Falkland Islands are named in honor of Robert Fitz-Roy, 
meteorologist, hydrographer and cartographer, commander of the expedition around the world ship "Beagle".

The name of the Ukrainian Mykola Miklukho-Maklay has a section of the coast of the island of New Guinea, which he explored in the period of 1871-1883. (Maclay's Shore). A Peninsula in Alaska, an island in Hawaii, a strait, a river and a mountain on Sakhalin are named in honor of Yuri Lisyansky, a geographer, oceanographer and navigator.

In Ukraine, settlements are mainly called in honor of prominent persons (Khmelnitsky, Ivano-Frankivsk, Dokuchaevsk, Chubinskoye, etc.), mountains and rocks (Dovbush Rock in the Carpathians, Levashovska mountain in Kyiv).

\section{Astronomical nomenclature}

The names of the brightest objects in the sky appeared much earlier than the earth's geographical names. People began to travel long distances not at once, so the idea of the structure of the earth's surface and its details were formed gradually. And the sky from the earliest eras was available for contemplation in every inhabited corner of the Earth. For orientations in space and time, the ancient inhabitants of planet remembered the bright configuration of the stars, gave them names in accordance with the similarity with earthly objects (Spica-from the Latin "ear of wheat") and the deities worshipped (Mars — the ancient Roman God of war). Objects with fast movements - Sun, Moon and bright planets, attracted attention in the first place, so each nation had its own names for them. With the appearance and development of science, the centers of which in a certain way migrated around the planet with the rise and fall of states and civilizations, many names were lost, some were transformed, others remained stable. Each culture had its own specific rules to give names. So, for example, there are the names of some constellations, bearing the names of the heroes of Greek myths: Cepheus, Andromeda, Cassiopeia, etc. The ancient Arabs had a descriptive principle of the location of the star in the constellation. For example, star Rigel is translated from Arabic as "leg", in the constellation of Orion, it is just where the hunter's leg should be.

Each star received many variants of designations. There is about a thousand historical and traditional star names, which were used as a kind of astronomical slang (Furud, Muscida, Parma), national names (e.g., the North star in Estonian is Phanuel, in hakushu - Hoschar, in Yugoslav - Nekretnina, in the language of the Northern peoples — Bug Sangan, in Ukrainian- Kil).

The brightest star of the constellation Kiel, visible in the southern hemisphere - well known Canopus is also called Ptolemeon, Pandrosus, Suheil, Alsachl, Gubernaculum, Vasn, Proclos, Terrestris, etc.

Some of the names have undergone a certain transformation over time, for example, the primary names of stars in the constellation Cygnus in Arabic meant (as indicated in the catalog of 1030) "Bright on the tail", "Chest", "Elbow of the right wing". But over time, the names were reduced to one word and the stars were called: Deneb, Sadr, Giyanah. Other stars have several common names associated with the peculiarities of transliteration. For example, the Dawn of the Orion constellation Alnilam is called Lenihan and Alnilam.

In Ukraine has long been used both a set of astronomical names, translated from the Greek language [Yzbornyk, 1983], and astronyms — folk names of planets and constellations, for example, the Well — the constellation of Dolphin; Volyar — the constellation Volopas; Harrow - the constellation Cassiopeia; and others [Naienko, 2016; Klymyshyn, 2006]. 
With the development of astronomy and international cooperation, it became increasingly difficult to identify the objects of research of different authors, because different national and proper names of stars were used, and constellations in general had different layout and their number was not constant. To somehow generalize information about the stars, the Italian astronomer Alexandro Piccolomini published the first Atlas of the starry sky and proposed to designate the stars in the constellations by the letters of the Greek and Latin alphabets in descending order of their brilliance [De le stelle, 1540]. His successor, the German astronomer Johann Bayer continued this innovation and expanded in his Uranometer [Bayer, 1603]. Astronomer Greenwich Observatory (England) John Flamsteed in 1712 proposed another approach for unambiguous designation of stars - to number the stars with Arabic numerals in each constellation in ascending order of one of the coordinates of the star from west to east [Flamsteed, 1712].

In the future, new star catalogs appeared and the stars in them had their own numbering. For example, for Sirius - a Canis Majoris, and Big Dog, BD -16²1591, ADS 5423.

\section{International astronomical regulatory bodies}

In 1919, the International Astronomical Union (IAU) was founded at the Founding Assembly of the International research Union (IAU) [Andersen et al., 2019]. Today it is an Association of 13551 specialist astronomers from 107 countries. This organization has become recognized as the highest international authority in dealing with astronomy issues requiring cooperation and standardization. In particular, it is the IAU that decides on the official names of celestial objects and details on the surface of Solar system bodies.

So in 1922, at the meeting of the first General Assembly of the IAU, a Committee on astronomical nomenclature was established and it was decided to prioritize the division of the celestial sphere of the northern southern hemispheres into constellations. By that time there was no unambiguous definition of their boundaries, moreover, even the number of constellations in different countries at different times was different - from 47 in Ptolemy to 237 in Mongolia. A special commission divided the sky according to certain rules into 88 sections. The official names for each constellation, their boundaries, spelling and abbreviations were fixed, and the stars visible from Earth in each of the constellations were listed. The work was completed in 1928, and in 1930 the standards of constellations were officially published and have not been changed since then.

In 1935, the Committee presented the first systematic list of monthly nomenclature [Blegg \& Müller in 1935,]. Later, with the launch of artificial satellites, this list was expanded and refined [Arthur et al., 1963; Arthur et al., 1966].

The Martian nomenclature was refined in 1958, when a special Committee of the IAU recommended for adoption the names of 128 Martian formations, which differed in color and brightness, and which were observed with ground-based telescopes. The beginning of the work was performed at the end of the 19th century by the Italian astronomer Giovanni Virginio Schiaparelli.

Since the advent of space missions made it possible to study in detail the surfaces of the planets of the Solar system and their satellites, a permanent Commission of planetary nomenclature to ensure the normalization of the names of parts to certain standards began to operate at the IAU since 1957. 
At the AMIS meeting in Sydney in 1973, the nomenclature group was reorganized and the work expanded. Working groups for Moon, Mercury, Venus, Mars and bodies that move outside the Solar System, began to operate to conduct preliminary work on the selection of themes and proposed names for formations on each planet and satellite [De Vaucouleurs et al., 1975; Tarter, 2005]. In 1984, in order to be able to name surface features on small bodies (asteroids and comets), another working group was established [Masursky et al., 1986]. Since 2012, all of them have been operating in the structure of the IAU Department F — Planetary systems and astrobiology.

\section{The names of the stars}

In the late 1990s and early 2000s, a wave of outrage by astronomers swept the world due to the fact that some dubious firms and companies began to arrange the so-called "sale of stars". For a fee, the buyer received from the representatives of these entrepreneurs certificates with ordered own names of stars. Sometimes in such "sold" lists even bright stars with the centuries-old set name were taken. And the observatories began to flock to the "owners" of stars with the requirement to show them their star. To clarify the situation in this matter on the official website of the IAU even a special page explaining such charlatanism was created. And in 2015, under the division C - "Education, enlightenment, history and heritage" a working group "Names of stars" (Division C WG Star Names, WGSN) was established. It consists of astronomers who have experience with stellar astronomy, recognized experts in the history of astronomy who study astronomy in the culture of the peoples of the world. The group has set itself the goal of cataloguing and standardizing proper star names for the international astronomical community. The names will be based on a great historical and world cultural heritage through the study of archival data and literature on astronomy.

The working group was empowered to establish guidelines on the proposals and adoption of names for stars, to harmonize and summarize historical star names, to collect and maintain, publish and distribute official catalogues of names of stars and exoplanets.

Up to early 2019, the WG has officially approved its own 336 star names, a catalog of which can be found on the official WGSN [Observer's Handbook, 2018]

There you can also ask a question and get an exhaustive answer about the origin of a particular name of the star and the rationale for such a choice out of many names. The group's work continues, new research and approved titles are printed annually in WGSN Bulletins.

While carefully studying the newly created catalog you can see that a small part of the stars still bears the names of specific people. But these are special stars that have certain unique features. And they are officially named in honor of the discoverers and researchers of these non-standard objects. Among the stars with names of real persons, the most famous is Barnard's star, or Barnard's flying star from the constellation Ophiuchus. It was discovered in 1916 by American astronomer Edward Emerson Barnard. Invisible to the naked eye, the red dwarf has the largest proper motion of any known star on Earth. For 180 years, this star has changed its location among other stars by the magnitude of the apparent diameter of Moon, such a path other stars overcome on the earth's sky for almost a thousand years.

Earlier in 1897 it was discovered by the Dutch observer Jacobus Cornelius Kapteyn and also named in his honor the star Kapteyn in the constellation of the Painter. Its peculiarity is that it not only has a sufficiently large own motion, but also rotates around the center of the Galaxy in the direction opposite to the movement of the vast majority of objects, thus moving 
away from the Solar system at a speed of $245 \mathrm{~km} / \mathrm{s}$. The uniqueness of the Scholz star, or rather a small binary star system, which has a total mass of only 0.15 masses of the Sun, is that it has an unusually small own motion. This feature was noticed in 2013 by German astronomer Ralf-Dieter Scholz and calculated that 70 thousand years ago this system was very close to the Sun (0.8 light years). The star of Leighton, the stars of Teagarden, van Maanen, Innes, van Bisbrouck, Przybylski, Krzeminski, Popper also have their exceptional features. Yet the vast majority of stars bear names of ancient Greek, Arabic and medieval origin.

\section{Conclusions}

Scientists interpret the problem of astronomical nomenclature in different ways, emphasizing that nomenclature lists are not a systematized whole, but only a catalog of registered concepts. Nomenclature names in each terminosystem have their own characteristics, they are often incommensurable, and therefore can not be reduced to one group.

Among the astronomical terms a lot of proper names, which are the names of stars, constellations, planets are recorded and formed by lexico-semantic way based on:

1) the names of animals, birds, insects, amphibians;

2) the names of objects and their parts;

3) the names of professions or occupations.

On the basis of metaphorization astronomical nomen-phrases were created, among which we can point out:

1) names of constellations;

2) names of aquatic facilities, identified on different planets.

Thus, astronomical nomenclature is a full-fledged part of astronomical terminology, since the scientific astronomical nomen has the same characteristics that the term has: exact correlation with a certain scientific concept, the presence of a definition, system (each nomenclature name occupies a certain place in the hierarchy of astronomical noumenons), unambiguity, the absence of homonyms as undesirable elements in terminology.

Thus, natural formations on Earth and in the sky are subject to national and international legislation both in their use and in the naming rules. Humanity has recognized this for a long time, and anyone has no right to violate this order.

\section{References}

Andersen, Johannes, David M. Baneke, and Claus Madsen. The International Astronomical Union. Uniting the Community for 100 Years. Springer, 2019.

Arthur, D. W. G., Agnieray, A P., Horvath, R. A., Wood, C. A., and Chapman, C. R. The system of lunar craters, quadrant I. Communications of the Lunar and Planetary Laboratory. V. 2, no. 30, 1963: 71-78.

Arthur, D.W.G., Pellicori, R.H., and Wood, C.A. The system of lunar craters, quadrant IV. Communications of the Lunar and Planetary Laboratory. V. 5, no. 70, 1966: 1-208.

Bayer, Johann. Uranometria omnium asterismorum continens schemata, nova methodo delineata aereis laminis expressa. Augsburg: excudit Christophorus Mangus, 1603.

Blagg, Mary, and Karl Müller. Named lunar formations. London, Percy Lund, Humphries \& Co. Ltd., 1935. De le stelle fisse di Alessandro Piccolomini viene stampato per la prima volta a Venezia nel, 1540 
De Vaucouleurs G., J. Blunck, M. Davies, A. Dollfus, I. K. Koval, H. Masursky, S. Miyamoto, V. I. Moroz, C. Sagan, and B. Smith. The new Martian nomenclature of the International Astronomical Union. Icarus. V. 26, 1975: 85-98.

Flamsteed, John. Historia coelestis libri duo, quorum prior exhibet Catalogum Stellarum Fixarum Britannicum et Planetarum omnium Observationibus; posterior Transitus Syderum, 1712. London: J. Matthews; VI, 507 p.

Klymyshyn, I. A. Istoriia astronomii. Ivano-Frankivsk: Hostynets, 2006.

Kodeks ustalenoi praktyky "Struktura ta zmist Derzhavnoho reiestru heohrafichnykh nazv". Visnyk heodezii ta kartohrafii. №4, 2009: 3-9

Konstytutsiia Ukrainy. Vidomosti Verkhovnoi Rady Ukrainy (VVR), 1996, № 30, st. 141

Masursky, Harold, Kaare Aksnes, G.E. Hunt, M.Y. Marov, P.M. Millman, David Morrison, T.C. Owen, V.V. Shevchenko, B.A. Smith, and V.G. Tejfel. Annual gazetteer of planetary nomenclature, Intenationl astronomical union, working group for planetary system nomenclature. U.S. Geological Survey Open-File Report, 1986: 84-692.

Naienko, H. Astronomichna terminolohiia u staroukrainskykh pamiatkakh pershoi polovyny XVII stolittia. Lviv: Instytut prykladnykh problem mekhaniky $i$ matematyky im. Ya. S. Pidstryhacha NAN Ukrainy, 2016.

Pro heohrafichni nazvy. Zakon Ukrainy. Vidomosti Verkhovnoi Rady (VVR), 2005, № 27, st. 360

Observer's Handbook 2019: USA Edition. By Editor James S. Edgar. Royal Astronomical Society of Canada, RASC, 2018.

Svitlychnyy, Olexander. Ownership of Space Objects. Advanced Space Law, Volume 2, 2018: 76-95. https://doi.org/10.29202/asl/2018/2/10

Tarter, Jill C. Nomenclature Scheme in use by the WGESP and a Current List of Extrasolar Planets. Highlights of Astronomy. Vol. 13, 2005: 1008.

Yzbornyk Sviatoslava 1073 hoda. Faksymylnoe yzdanye. Moskva: Prosveshchenye, 1983. 